\title{
Putting in Value Corporate Social Responsibility
}

\author{
Carmen Parra*, Joan Ripoll-i-Alcon ${ }^{* *}$, Guillem Marti ${ }^{* * *}$
}

\begin{abstract}
European companies have not only taken care of complying with the legal obligations imposed by the law (social and environmental obligations), but have gone further by voluntarily assuming a real commitment to their corporate social responsibility. In this sense, a set of indicators defines a real approach to CSR. In particular, a model to rate environmental, social and governance (ESG) dimensions of any company seems to provide an objective, measurable and comparable information that makes it possible to define a real assessment of the CSR based on ESG.
\end{abstract}

Keywords: Corporate Social Responsibility; CSR; Sustainability; ESG Model; Corporate Governance; Global Markets

\section{Assessing CSR}

Since the end of the twentieth century, worldwide companies have had the need to report on the social responsibility of their businesses. This trend has been promoted especially by Non-Government Organizations (NGOs) and other Social Institutions, very interested in to assess the impact of these global companies. Indeed, all they have claimed the lack of regulation and control in the social and environmental aspects of companies (Strandberg, 2010).

The European Commission (2001) defined corporate social responsibility (CSR) as "a concept whereby companies integrate social and environmental concerns in their business operations and in their interaction with their stakeholders on a voluntary basis". Since then, embracing CSR, European companies have not sought to comply with the legal obligations imposed by the law (social and environmental obligations), but have gone further by voluntarily making a real commitment to their social responsibility. At the same time, the NGOs as well as the Stakeholders have developed some recommendations and standards that should be taken into account in any attempt to put in value Corporate Social Responsibility (CSR).

These demands have forced companies not only to consider the social and environmental dimension into their daily management, but also to search some indicators to measure the results of the actions of this nature in a coherent, complete

\footnotetext{
*Full Professor of Social Business, Abat Oliba CEU University (cparra@uao.es)

** Full Professor of Business and Management, Abat Oliba CEU University (jripoll@uao.es)

*** Assistant professor of International Finance at PUCMM (guillemmarti@pucmm.edu.do)
} 
and orderly way. Nonetheless, it is increasingly important to provide a strategic approach to CSR in order to promote the competitiveness of companies (Brondoni, 2010). This challenge is to be more transparent, to report on risk management, cost savings, access to capital, customer relations, human resources management and innovation capacity. By assuming its social responsibility, companies can gain the lasting trust of workers, consumers and citizens and thus achieve a basis for developing sustainable business models. Increased confidence contributes, in turn, to creating an environment in which companies can innovate and grow (Ligteringen \& Zadek, 2005).

According to all these initiatives, there are currently several international initiatives that have tried to measure CSR. They include the Global Compact, Global Reporting Initiative (GRI), SA 8000, AA 1000 or ISO 26000 among others systems. However, none of these guidelines fully reflects the true scope of the non-financial activity of the companies.

The aim of this paper is to define a set of indicators that result in a real approach to CSR. In particular, we have built a model to rate environmental, social and governance (ESG) dimensions of any company. It also allows to provide an objective, measurable and comparable information that makes it possible to provide a real assessment of the CSR based on ESG.

This article is divided into five parts. Putting aside introduction, in the second section, we briefly describe the main reasons to measure CSR but we also explains how the myriad of CSR indicators that are not comparable makes it very difficult to understand clearly, what the meaning of CSR is. The third section suggests different ways of assessing the relationship between the companies and their environment that goes beyond CSR. In the fourth section, we deliver a valuation model based on ESG. Finally, the last section contains the main conclusions.

\section{Why is Important to Measure CSR}

The measurement of the non-financial results of companies has become in recent years as important a question as measuring their economic results (Chatterjiand \& Levin, 2006). It has strongly introduced the need to measure CSR as a real proof to demonstrate the business commitment with their social responsibility as well as to verify if their expected objectives have been achieved.

Nevertheless, to measure means outlining the objectives of the company through ponderable values that allow us to define a system of indicators. Indicators that should be understood as a set of values designed to measure specific variables that allow us to verify that a company can reach its strategic goals (Strandberg, 2010).

Therefore, the chosen indicators should be useful both for the decision making of the companies and for communicating these results to the stakeholders (Lopatta, Jaeschke et al., 2017). This external communication always provides transparency to the companies' performance converting them into competitiveness factors, which are key in the process of creating value. In that case, CSR could became a tool for reaching the excellence in management as well as to differentiate certain companies from the rest of their competitors (Rosanas, 2006 and 2010; Flammer, 2015).

These set of indicators also allow to evaluating the companies' social results by offering information to different stakeholders. For example, customers could get 
some information about the origin of the products, who makes them and who produces them. On the other hand, employees and governments know the social and environmental responsibilities that the company must assume (Mitchell, Agle et al,1997; Edmans, 2012).

However, the reliability of the chosen indicators requires their incorporation into standards recognized by society. This means that if a company is measured under its own criteria, instead of an established standard, it must explain how the indicators have been identified and measured to demonstrate that it meets the minimum social, economic and environmental standards. Therefore, it is considered more reliable to incorporate a rule considered legitimate that offers credibility to the company by adapting to established requirements accepted by society. An established measurement system that makes it possible to delimit indicators, to agree procedures and to establish clear rules that demonstrate the existence of a transparent system (Rasche, 2009).

\subsection{Too Many Csr Indicators, too much Information but any Fully Reliable}

The indicators are an useful tool to measure impacts and to summarize results, hence the importance that they serve to evaluate the life cycle of companies, helping to measure their progress and to know if they are reaching their objectives (Keeble, Topiol et al. 2003). In this way, the management could know if it is executing correctly its strategy correcting those areas or processes that do not meet expectations.

To assess the value of the indicators, Ligteringen \& Zadek (2005) argue that the use of CSR indicators serves to help managers and to implement responsible and transparent business practices, as well as to provide a clear vision of the main goals of sustainable development and CSR.

However, based on some criteria there is a risk that the measurements become an integrated set of objectives and measures agreed by the management of the company that only aim at short-term results offering what stakeholders want to hear in this precise moment. Hence the importance of having universal and pre-established standards that allow us to use neutral and reliable indicators for all companies (Nidumolu, Prahalad et al. 2009).

The measurement of CSR must depart from the dialogue and consensus of the stakeholders and not from a legislative initiative that would respond to economic ideologies and policies of the government in power. Therefore, CSR rules must respond to measurement, disclosure and accountability criteria vis-à-vis internal and external stakeholders that in turn reflect the CSR main objectives. The values that reflect the performance of the company according to its reputation and its moral quality must be taken into account too (Knox \& Maklan, 2004; Dyck, Lins et al. 2015).

According to these guidelines, it has been created a myriad of standards responding to different criteria. However, the difficult to compare each other has ended up confusing stakeholders when they try to choose the company best value in terms of SCR. For the time being, it has been shown that adding one more certification does not add value to the companies' transparency, but rather that the requirement to implement different standards hinders and slows down their work. According to Kolk (2004) the indicators built to assess companies' CSR are different but compatible, 
responding to different stages of the process towards a more responsible and sustainable organization. In this sense, there are different classification systems taking into account their approach, measuring mechanism, or analyzing sectors (economic, social, and environmental). It means that some auditing process are required to reach a fair evaluation and verification of results to ensure their validity (Gjoldberg, 2009).

The aftermath of all these attempts has been the proliferation of guidelines and standards that measure the impact of CSR and an increasingly widespread practice among companies through integrated reports that cover at the same time economic, social and environmental aspects (Wang, Hsieh et al., 2017).

\section{CSR, Shared Value and ESG: Different Ways to Understand The Relationship Between The Companies and Their Environment}

In recent decades, different ways of understanding the relationship of the company with its environment have appeared: Corporate Social Responsibility (CSR), Shared Value and ESG are some of the titles that summarize different ways of understanding this relationship and different proposals to address them.

\subsection{Shared Value: A Practical Vision of CSR}

To the extent that CSR is presented as an eminently theoretical and descriptive concept, Porter \& Kramer (2011) propose a practical reformulation of CSR, which they designate as Shared Value. The underlying idea is that the interest of society is not opposed to the interest of the company .

While CSR pursues responsibility, the Shared Value focuses on the creation of value. Thus, the main contribution of the Shared Value is to move away from philanthropy or extra-business activities. According to Porter \& Kramer (2011), the Shared Value has to concentrate on the creation of wealth for the company, but always doing so in such a way that the social benefits of its actions outweigh the social damages that these may cause. In this sense, these authors point out that:

\footnotetext{
$\square$ "The purpose of the corporation must be redefined as creating shared value, not just profit per se. This will drive the next wave of innovation and productivity growth in the global economy". By comparison Porter and Hills (2011) consider that: "Shared Value measurement (...) does not rely on statistical correlations or estimated monetary values of environmental and social outcomes. Instead, the aim is to establish a direct linkage between social outcomes and actual financial results".
}

The Shared Value theory has aroused great interest in the business world, since large corporations find this concept much more related to their interests than the undefined and voluntarism concept of CSR.

However, Crane \& Matten (2014) are critical of Shared Value for two main reasons. In the first place, they criticize the lack of originality of the proposal, since they consider that the development of beneficial actions for society by companies is an 
idea included in CSR itself. Strategic CSR, Stakeholders Management and Social Innovation are all similar concepts to Shared Value, although with slightly different approaches. Secondly, Crane \& Matten (2014) consider the Shared Value proposal unrealistic since they start from the assumption that there is always a positive and optimal alternative for both society and the company. This relies on compliance with the tax obligations of companies, ignoring the fact that some companies that undertake initiatives in favour of society at the same time evade taxes or are condemned for breaches of other laws.

In addition, the Shared Value theory is simplistic because it ignores the complexity of the economy and competition in the capitalist system.

In any case, Shared Value can be understood as a step forward to defining and expanding the social responsibility of companies. But it is a deficient tool, too simplistic to measure social responsibility analytically and rigorously.

\subsection{ESG: Social responsibility as an investment}

ESG (Environmental, Social and Governance) is one of the concepts that have emerged because of the debate about the relationship that companies should maintain with society. There are different concepts that have been developed around social responsibility and all have a certain similarity.

While CSR is a vague concept, ESG incorporates three dimensions: Environmental, Social and Governance, a clear statement of intentions: social responsibility, environmental conservation policies, respect for society and good corporate governance (Salvioni et. al, 2014).

These three pillars structure the socially responsible activity of the company, that is, the concretion of a common, orderly and rigorous idea about the collaboration of companies in the correct development of the economy and society.

ESG is based on the same nature of voluntariness, ethics and philanthropy that defines CSR. Thus, the United Nations (2007) define ESG “(...) as a proxy for management quality, in so far as it reflects the company's ability to respond to long term trends and maintain competitive advantage". A concept that is further strengthened by the United Nations Principles of Responsible Investment:

\footnotetext{
"Analysis and evaluation of ESG issues is a fundamental part of assessing the value and performance of an investment over the medium and longer term, and that this analysis should inform asset allocation, stock selection, portfolio construction, shareholder engagement and voting. Responsible investment requires investors and companies to take a wider view, acknowledging the full spectrum of risks and opportunities facing them, in order to allocate capital in a manner that is aligned with the short and long-term interests of their clients and beneficiaries".
}

Consequently, ESG is not a philanthropic concept but rather aspires to be a tool of analysis with which companies can obtain greater benefit by correctly managing their context and making strategic projections in the medium and long term. In particular, the objective of a company is to obtain yields that make it attractive to investors, while offering consumers competitive products and services (Barko, Cremers et al., 2017). However, the criteria of ESG aim to guide the company 
towards business actions that are beneficial to society without for this reason having to give up maximizing their profit. In other words, the criteria of ESG do not seek in any case that the company should pursue a vocation of philanthropy or charity. These tasks have been assumed by the State and by other types of very specific organizations such as NGOs and foundations.

Certainly, many large companies in Eastern and Western Europe have created foundations that nurture on donations and develop tasks of enormous importance to society (Mosca et al, 2015). Undoubtedly, the social benefit that these initiatives represent must be recognized, but it should not be confused with ESG.

Companies that undertake philanthropic tasks seek to obtain profits through a business that does not follow any criteria of social responsibility to subsequently allocate a small part of these profits to philanthropic and charitable purposes with the motivation to achieve fiscal incentives and at the same time clean up the image of the company. It is a model only suitable for large companies and that has been particularly exploited by the banking sector. It is surprising to see how large banks that due to their business model enjoy little popularity allocate resources to their foundations in an attempt to improve their image.

The model promoted by ESG moves in another direction, since it seeks to include within the decision-making processes of the companies a series of criteria that currently receive little consideration (Knox \& Maklan (2004); Bassen \& Kovacs, 2008; Lee, Cin et al., 2016).

ESG has many similarities with the Shared Value, but distances itself from it at the points where Crane \& Matten (2014) were more critical. ESG does not attempt to change the relationship between the company and the market, nor does it aspire to renew capitalism. ESG is presented as a simple analysis tool, capable of capturing part of the complexity of the free market. By clearly defining three pillars (environmental, social and governance), it will not consider socially responsible a company that takes a positive initiative for the development of society in isolation, but will require it to comply with each and every one of the defined pillars, including compliance with legal and tax obligations.

\subsection{The Three Pillars of Esg: Environmental, Social and Governance}

Hartman and Morland (2007) described for the first time the the so-called Triple Bottom Line of RSC: Economic, Social and Environmental. According to this previous work and taking into account some recommendations of others authors and institutions, we consider as the UN (2007) more suitable to assess SCR using another the three pillars: Environmental (E), Social (S) and Governance (G) because in our opinion ESG described better the qualitative and quantitative fundamentals of SCR.

\subsubsection{Environmental}

ESG considers the environment as one of the cornerstones of corporate social responsibility. In response to growing concern for the conservation of the environment, companies measure their actions more and more depending on the impact they will have on nature. To achieve this, environmental legislation promoted by governments has been of vital importance, without underestimating the role played by citizen pressure and responsible consumption. 
It is this pressure from governments, society and consumers that gives so much relevance to the environmental pillar of ESG. A company that does not correctly manage demands this field will face serious problems to survive. On the other hand, a company that adapts quickly to changes in the environment, becoming a paradigm for the conservation of the environment, will obtain great advantages over its competitors.

The environmental dimension covers a wide variety of fields, among which we can mention the protection of ecosystems such as tropical forests and seabeds and the protection of endangered species. These are very attractive topics to exploit commercially due to the seriousness and tangibility of their consequences. However, in the practical aspect in general, ESG should take into account, rather, daily problems such as emissions of pollutant gases, management of toxic waste, discharge of wastewater and level of recycling (Larkin, 2003).

\subsubsection{Social}

The second of the pillars that support ESG refers to the social dimension. The social criteria of ESG refer to all those actions that relate the company to society.

This relationship between the company and society includes aspects such as hiring people with problems of inclusion, gender parity in the workforce, the use of child labour or the hiring for positions of responsibility of people living in the geographical area in which the company has its production centres.

A company that maintains a good relationship with its social environment can be favoured with sales increases thanks to the positive image it will be transmitting; it will be able to obtain permits and concessions more easily from the regulatory authorities; and it will even be in a position to obtain tax benefits to encourage this way of acting.

Two of the most important stakeholders (or members involved in the business activity) are workers and customers. Citizens constitute both groups, which is why it is important that the company maintain a good relationship with society. In a society with discriminated and marginalized groups, with high levels of social conflict, with legal insecurity and with corruption, it is possible that productive companies will be born, but it will be difficult for them to sustain themselves. In order for a company to prosper, it will require a constant labour flow and consumption volume as well as a political and legal stability that will hardly be achieved in societies such as the one just described.

Therefore, it can be affirmed that beyond the good image that allows it to project, acting in accordance with the interests of society will help the company to collaborate to create a solid social base on which to base the business. Actions such as the incentives for having children and non-discrimination in hiring based on gender, race or religion, will avoid the relocation of production centres away from their markets and will promote medical research and education (Liern, Pérez-Gladish et al. (2017).

\subsubsection{Governance}

The third and final pillar of ESG is governance. This refers to the good management of the company itself, the creation of a solid and stable business structure through labour policies, management of teams and respect for the legal framework. 
Therefore, the criteria of ESG in terms of governance will be linked to labour disputes, the levels of salary paid to each category of workers, respect for collective agreements and unions, clarification of responsibilities if executives are condemned by the justice system, and policies against fiscal fraud and corruption.

Considering these criteria when designing policies to govern the company will help to promote management and work habits that favour the productivity and stability of the company, preventing internal tensions and bad practices that may lead to strikes or public scandals.

Such situations seriously damage the image of the company before stakeholders and particularly weaken the confidence that customers and investors may have. Without the support of the latter, any company will be doomed to failure. Therefore, it is vital to eliminate any possible situation of risk (Turner, 2013). In addition, as in the previous sections, it can be observed that respecting legislation and promoting good practices within the company is not a need with a moral basis but rather, primarily, an economic motivation (Lambin, 2009).

\section{ESG Valuation Model}

\subsection{Introduction}

To overcome these difficulties, this article presents a rating model called ESG Audit, based on the actions of the companies and not on their intentions.

The aim is to measure the quantitative and qualitative areas that provide objective, measurable and comparable information that enables us to obtain a real picture of the company in terms of ESG, and is capable of describing its evolution over time. Following Strandberg (2010), we have established three criteria to take into account in the model implementation and monitoring: a) the reliability, b) comparability and c) validity of the indicators.

a) Reliability: it refers to the possibility that companies give the same answer when the indicator is applied more than once. The method used is based on surveys. However, the answers offered could vary from time to time depending on the moment or the people who answer them.

b) Comparability: to be comparable every indicator must be homogeneous once it has been used at different times and by different companies. This requirement allows us to establish a ranking of companies, evaluate their activities or identify key issues of CSR in terms of ESG.

c) Validity: it is fulfilled when the indicate measures what it has been created for. However, the indicator sometimes depends on the context where it is applied, not having a global scope.

The indicators on which CSR is valued are numerous, highlighting organizational governance, human rights, labor practices, the environment, fair operating practices, consumer interests and community participation. For each of them, a general overview, a description of the indicator as well as the activities and expectations that should be developed are offered. It is a rule that guides on how to put into practice the social responsibility of the company being its biggest criticism not being certifiable. 
Considering all the above, the main idea of the present article is to define a system of indicators that are easy to measure and comprehensible for the greatest number of companies. It should also serve to report periodically about the status of companies' CSR by offering a useful and reliable certificate that is accepted by the business network.

In our opinion, the measurement system of the CSR must incorporate the four basic principles.

a) The valuation instrument should contain easy and flexible indicators to allow adaptation to the particular circumstances of each company. For this, it is preferable to use specific indicators that facilitate their verification.

b) Legitimacy: This criterion is reached through the mutual communication of the stakeholders interest offering an accurate and useful information.

c) Easy to understand processes. Specific and compatible with existing resources in the company that allow evaluation procedures serving to contrast the results of the standards.

d) Geographical and sectoral environment. These standards can be used according to national legislations or in relation to specific aspects where the impacts are internationally recognized.

\subsection{Criteria to Measure Csr Through the Creation Of Indicators}

We have defined a series of variables whose information comes mostly from public and testable sources. The so-called ESG Audit model is based on 30 variables concerning different aspects of the environmental, social and governance fields.

This set of 30 variables that we have selected is not arbitrary. On the contrary, they have been chosen considering most of the standardized and consensus items in relation SCR. Our analysis is based on a) UN Global Compact, b) Global Reporting Initiative, c) Accountability's AA1000 Series, d) SA 8000 Standard, e) Standard SGE 21 and f) ISO 26000.

a) Global Compact: It brings together a set of Principles of CSR (10 Principles) implemented by the United Nations since 2000 with the purpose of getting companies to voluntarily achieve social and environmental impacts. The Global Compact is divided into four areas: human rights, labor standards, the environment and the fight against corruption. Through the Global Compact, companies commit themselves to prepare every year a Report to implement the ten principles and to self-assess their management. With this, it is possible to provide the company with greater credibility and transparency. It is applicable in all sectors and regions of the world; its success is derived from the reputation of the UN, however it has been subject to numerous criticisms such as using only external indicators, using unclear indicators and being a norm of a political nature ${ }^{\mathrm{ii}}$.

b) Global Reporting Initiative (GRI): It is an organization created by networks of North American investors with a strongly environmental character with the support of United Nations Program for the Environment (UNEP). Unlike the Global Compact, the GRI includes economic and social impacts. The GRI guidelines are based on four principles: materiality understood as that the reports must cover aspects and indicators that reflect the most significant impacts (economic, social and environmental). Stakeholders that identifies them and describes their expectations and interests. Sustainability that respects environmental principles. 
Comprehensiveness that implies the use of indicators that reflect the true results of the company. The GRI has been criticized because the certification only serves to verify whether the Report meets the requirements or not, but does not investigate the veracity of the information. On the other hand, it does not establish requirements regarding who performs the external audit, placing emphasis on the guarantees offered by the stakeholders. In addition, the guidelines do not have guidelines on the management of culture and business ethicsiii.

c) Accountability's AA1000 Series: They were created by the Account Ability Institute in order to help companies assume a responsible and transparent attitude by establishing a framework that allows the company to identify, prioritize and respond to the challenges of sustainability. To achieve these objectives, a professional methodology has been created to assess the nature and degree of adherence to the Accountability Principles (AA1000APS). The Accountability Principles are three: Inclusivity for the company to accept responsibility for everything that generates an impact in relation to its stakeholders and sustainability. Relevance that allows determining the importance of relevant matters for the company and for the Stakeholders. Ability responding to issues related to sustainability. The mechanism used to achieve the principles are the assurance standards (AA1000AS) and the commitment with the stakeholders (AA1000SES). Through them, a standard of general application is obtained to evaluate, testify and strengthen the quality of the Reports. The criticism is related to the difficulty in using its indicators, its complementary elements and its connection with other norms ${ }^{\mathrm{iv}}$.

d) SA 8000 Standard: It was created in the 1990s by the Social Accountability International (SAI) to create global measurement standards for the worker's human rights. The SA 8000 aimed to establish a unique model with the support of the (International Labor Organization (ILO) oriented to social impacts especially child labor, forced labor, health at work, etc. The standard establishes specific criteria for each issue by clearly defining all the concepts it uses. It is certifiable with a validity of three years and audits every 6 months through interviews with employees and a system of claims. The main criticism it receives is its focus on working conditions ${ }^{v}$.

e) Standard SGE 21: It is an ethical and socially responsible management standard developed in the nineties by the Foroética organization that brings together professionals, companies, academics and NGOs. It is in continuous review process based on the accumulated experience. The SGE 21 standard analyzes nine areas of management: senior management, customers, suppliers, people who make up the organization, social environment, environmental environment, investors, competition and Public Administrations. For this, it uses three essential elements: its integration in the organization's strategy and processes, the promotion of dialogue and knowledge of the expectations of the Stakeholders and the promotion of transparency and communication. The first ethical and socially responsible management system allows voluntarily achieving a certification for both the company in general and for a part of the management system such as quality, environment, occupational risk prevention or innovation among others ${ }^{\mathrm{vi}}$.

f) ISO 26000: Since 2010, it aims to develop an international consensus on what CSR means, what issues companies should develop and how they can disseminate information on good practices. It is therefore a standard created to guide on the principles of CSR. 
At first the idea was to make the ISO 26000 a management standard based on existing standards (ISO 9000 quality standard management systems and ISO14000 on the environmental management system). However, it was finally decided that it was a non-certifiable guide ${ }^{\text {vii }}$.

\subsection{Defining the variables of the ESG Audit model}

In the following sub-sections, the 30 variables that define the ESG Audit model are defined and grouped according to their membership of the Environmental, Social or Governance pillars.

For each, we describe the information necessary to calculate it, the sources from which this information will be extracted, the sources through which it will be possible to compare, the quantification process that should be followed and the way in which alphabetic qualifications will be obtained.

\subsubsection{Variables of the Environmental Pillar}

The variables that belong to the Environmental group refer to the relationship that the company maintains with the environment. Of the many variables that could intervene in this category, we have selected those that offer a broader and more transversal view of a field as diverse as the environment.

In general, the alphabetical assessment (VA) of each of the variables $\left(E_{j}^{i, t}\right)$ that integrates the Environmental dimension of any company " $i$ ", in a year "t", responds to the transformation function detailed below:

$$
\text { (1) } V A E_{j}^{i, t}=f\left[E_{J}^{i, t}\right], \text { con } \mathrm{j}=1,2,3, \ldots ., 10
$$

The 10 variables that will define the Environmental category in the ESG Audit model are the following:

Table 1: Environmental Variables

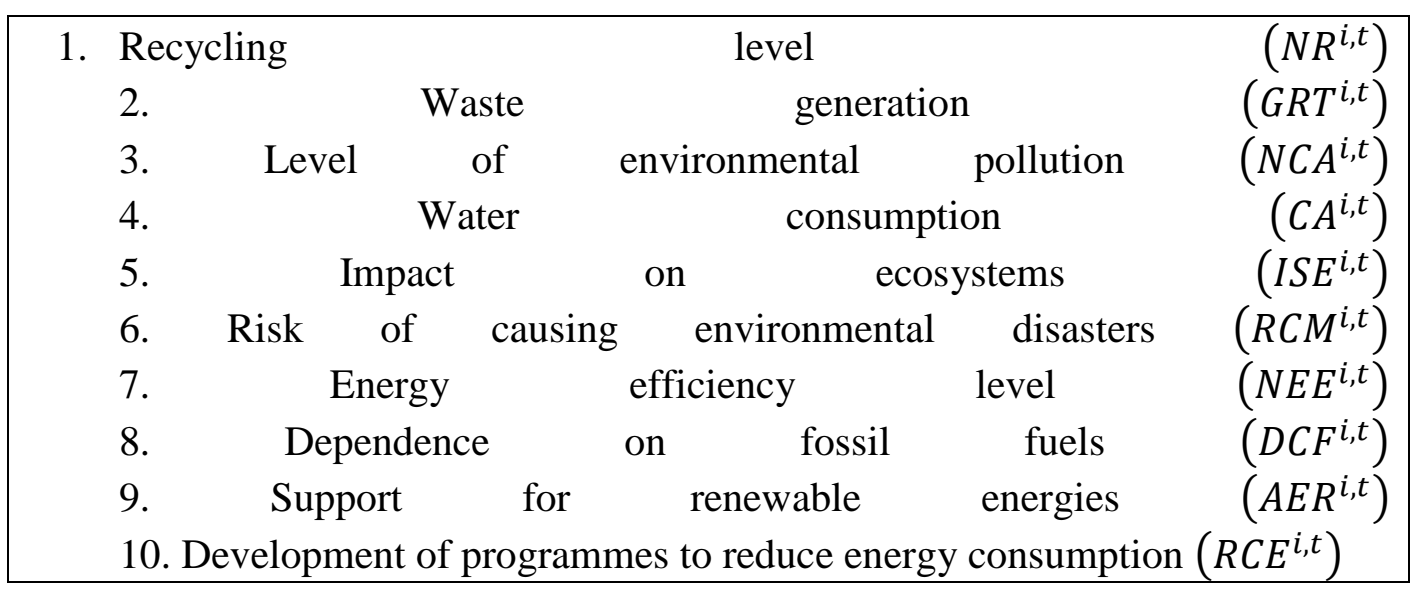

\subsubsection{Variables of the Social pillar}


The variables that make up the Social pillar will try to describe the relationship that the company has with the society. This is a very diverse field where the choice of variables that meet the criteria of representativeness and relevance has prevailed.

In general, the alphabetical assessment (VA) of each of the variables $\left(S_{j}^{i, t}\right)$ that make up the Social dimension of any company "i", in a year " $t$ ", responds to the transformation function detailed below:

Table 2: Social Variables

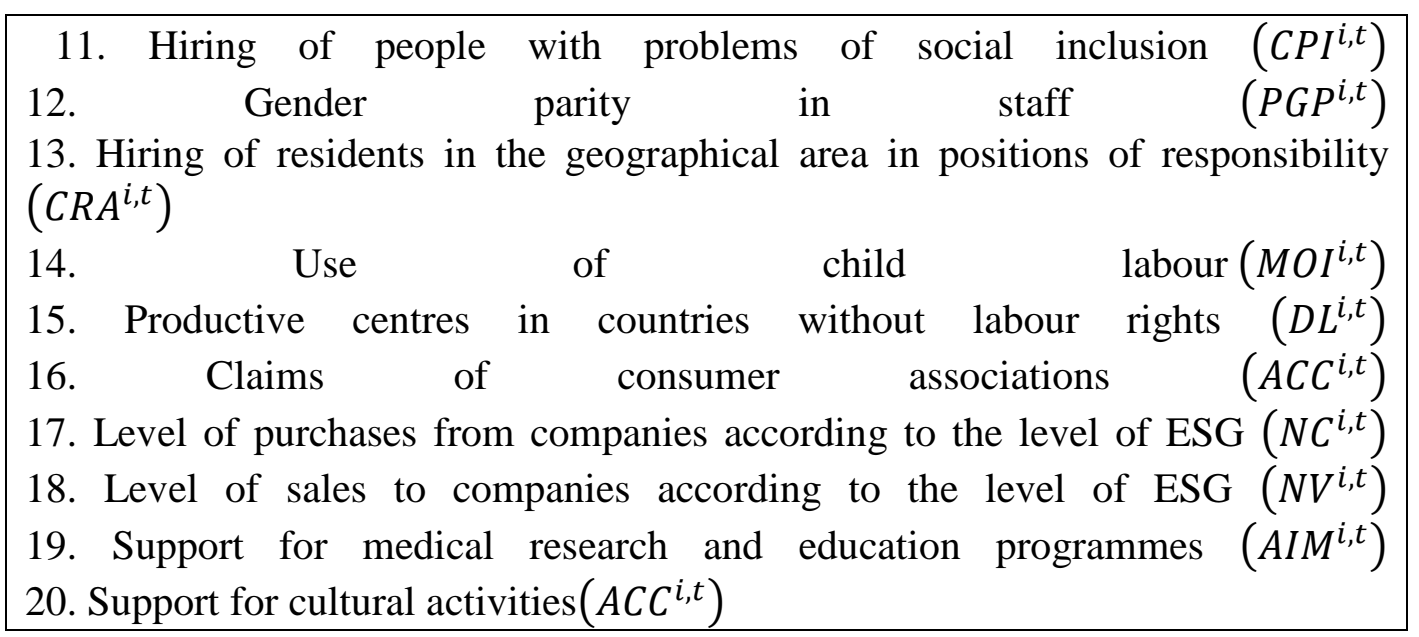

\subsubsection{Governance Pillar Variables}

The third pillar is that the Governance, referred to corporate governance decisions. It will include variables that expose the treatment of the company with its workers and the respect of the company towards the legal framework. The choice of those variables representative of the corporate culture of the company has prevailed.

In general, the alphabetical assessment (VA) of each of the variables $\left(G_{j}^{i, t}\right)$ that make up the Governance dimension of any company "i", in a year "t", responds to the transformation function detailed below:

$$
\text { (3) } V A G_{j}^{i, t}=f\left[G_{J}^{i, t}\right] \text {, con } \mathrm{j}=1,2,3, \ldots ., 10
$$

The corporate governance variables that will be included in the ESG Audit model are described in the following table:

Table 3: Governance Variables

21. Level of strikes $\left(N H^{i, t}\right)$

22. Difference between the wages of the workers and the minimum fixed in the agreement

23. Leave due to work accident $\left(B A L^{i, t}\right)$

24. Level of maternity and paternity benefit $\left(N P M^{i, t}\right)$

25- Relationship with tax havens and offshore investments $\left(R P F^{i, t}\right)$ 


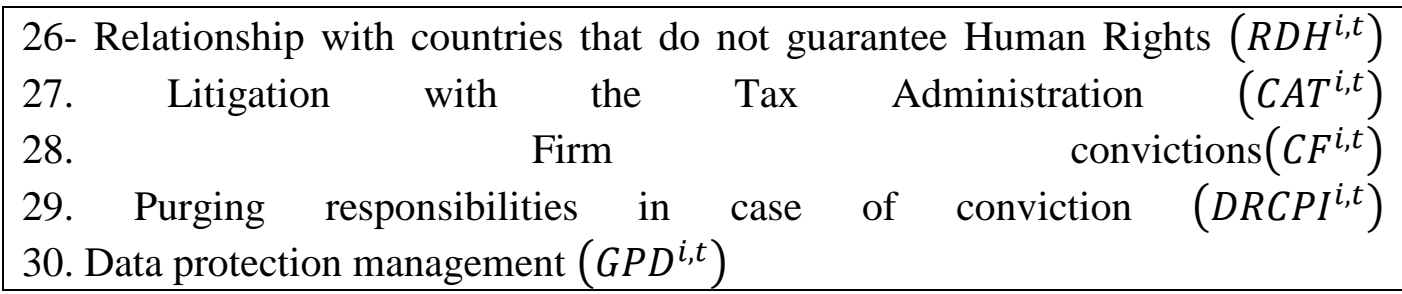

\subsection{Methodology}

At this stage of our research, we suppose for simplicity reasons that all three dimensions as well as all the 30 variables embodied in the model will have the same weighting.

Once the individual ratings have been defined for each variable, we can obtain very useful information. The individual ratings enable us to quickly and easily determine what type of relationship the company has with its context. We can see the strengths and weaknesses.

They can be grouped into different partial values to obtain specific information on specific topics. They also enable us to compare the ratings with other companies in the sector. Finally, it can be useful in the medium term to analyse the development and improvements that the company may be implementing with regard to its relationship with the context over time.

To make the information obtained in the ESG Audit model even simpler and more comparable, the last step will be to offer a global rating of the company. A simple formula rates ESG into four different grades ranging from A, B, C or D., where A is the highest and $\mathrm{D}$ the lowest will be used to process each of these variables.

This may be A, B, C or D, in which $\mathrm{A}$ will be the best score and $\mathrm{D}$ the worst. Offering four possible qualifications aims to highlight, as already explained during the previous sections, that the ESG cannot have a dichotomous assessment.

The individual qualifications of each variable of ESG will allow comparing them for different periods or between different companies. Grouping the qualifications of certain variables can obtain information on different kinds of criteria linked to ESG.

The qualification of the different variables will allow obtaining a global rating of the behaviour of the company with its context. It will be an assessment that will synthesize the ESG of the company and that will allow it to be easily compared with that of other companies or to prepare temporary, sectorial or other statistics.

Each of the three pillars of ESG will be analysed from 10 different variables. To choose all 30 of these variables, four criteria have been prioritized: representativeness, simplicity, reliability and quantifiability.

a) Representativeness: The variables must deal with very different aspects within each of the three pillars of ESG in order to obtain broad and relevant information on the company and its environment.

b) Simplicity: The information necessary to make the calculations of rating must be easy to obtain.

c) Reliability: The information used must be verifiable through two different sources or be obtained from official documents submitted to the Public Administration.

d) Quantifiability: The data obtained must be simple to process so that they can be converted into quantifiable values. 
Approving or suspending a company in terms of ESG gives very little information about its operation. However, if, instead of approving or suspending, a scale is provided, then each person, company or institution that wants to use the information resulting from the ESG Audit model will be able to decide what their minimum ESG requirement is.

This methodology of analysis and assessment of ESG is aimed at providing tool to internalize the negative and positive externalities generated by a company in the exercise of its activity. The ESG Audit model seeks to determine the social responsibility of the company, not the effort it makes to improve it.

It will be important that when assessing the rating, compare the score of a company analysed with other companies in the same sector. The individual values of the 30 variables will contribute to forming an in-depth vision of the ESG of the company, which in turn will also help to discover the company's efforts to improve.

By converting the individual values into numerical values, the detailed analysis of the different variables becomes easier. This will take place as described below.

The conversion of the alphabetical valuation $\left(V A E_{j}^{i, t}\right)$ of each one of the variables that make up the Environmental dimension of any company "i", for a year " $\mathrm{t}$ ", in a numerical valuation $\left(V N E_{j}^{i, t}\right)$ responds to the quantification function detailed below:

(4) $V N E_{j}^{i, t}=f\left[V A E_{J}^{i, t}\right]$, con $\mathrm{j}=1,2,3, \ldots ., 10$

So that $\left\{\begin{aligned} & V A E_{j}^{i, t}=A \rightarrow f\left[V A E_{j}^{i, t}\right]=4=V N E_{j}^{i, t} \\ & V A E_{j}^{i, t}=B \rightarrow f\left[V A E_{j}^{i, t}\right]=3=V N E_{j}^{i, t} \\ & V A E_{j}^{i, t}=C \rightarrow f\left[V A E_{j}^{i, t}\right]=2=V N E_{j}^{i, t} \\ & V A E_{j}^{i, t}=D \rightarrow f\left[V A E_{j}^{i, t}\right]=1=V N E_{j}^{i, t}\end{aligned}\right.$

Similarly, the conversion of the alphabetic valuation $\left(V A S_{j}^{i, t}\right)$ of each of the variables that make up the Social dimension of a company "i" any, for a year " $\mathrm{t}$ ", in a numerical valuation $\left(V N S_{j}^{i, t}\right)$ responds to the quantification function detailed below:

(5) $V N S_{j}^{i, t}=f\left[V A S_{J}^{i, t}\right]$, con $\mathrm{j}=1,2,3, \ldots ., 10$

So that $\left\{\begin{aligned} & V A S_{j}^{i, t}=A \rightarrow f\left[V A S_{j}^{i, t}\right]=4=V N S_{j}^{i, t} \\ & V A S_{j}^{i, t}=B \rightarrow f\left[V A S_{j}^{i, t}\right]=3=V N S_{j}^{i, t} \\ & V A S_{j}^{i, t}=C \rightarrow f\left[V A S_{j}^{i, t}\right]=2=V N S_{j}^{i, t} \\ & V A S_{j}^{i, t}=D \rightarrow f\left[V A S_{j}^{i, t}\right]=1=V N S_{j}^{i, t}\end{aligned}\right.$

Finally, the conversion of the alphabetic valuation $\left(V A G_{j}^{i, t}\right)$ of each one of the variables that make up the Governance dimension of any company "i", for a year "t", in a numerical valuation $\left(V N G_{j}^{i, t}\right)$ responds to the quantification function detailed below: 
(6) $V N G_{j}^{i, t}=f\left[V A G_{J}^{i, t}\right]$, con $\mathrm{j}=1,2,3, \ldots . ., 10$

So that $\left\{\begin{aligned} & V A G_{j}^{i, t}=A \rightarrow f\left[V A G_{j}^{i, t}\right]=4=V N G_{j}^{i, t} \\ & V A G_{j}^{i, t}=B \rightarrow f\left[V A G_{j}^{i, t}\right]=3=V N G_{j}^{i, t} \\ & V A G_{j}^{i, t}=C \rightarrow f\left[V A G_{j}^{i, t}\right]=2=V N G_{j}^{i, t} \\ & V A G_{j}^{i, t}=D \rightarrow f\left[V A G_{j}^{i, t}\right]=1=V N G_{j}^{i, t}\end{aligned}\right.$

Taking the numerical valuation $\left(V N E_{j}^{i, t}\right)$ of each of the variables that make up the Environmental dimension of any company "i", for a year "t", we can obtain the total numerical rating or rating $\left(R N E_{\text {Total }}^{i, t}\right)$ from the quotient between the sum of all and each one of the individual numerical valuations of that dimension and the number of variables (10) that make it up.

$$
\text { (7) } R N E_{\text {Total }}^{i, t}=\frac{\sum_{j=1}^{10} V N E_{j}^{i, t}}{10}
$$

This rating or total numerical rating $\left(R N E_{\text {Total }}^{i, t}\right)$ corresponding to this Environmental dimension will range between a minimum range of 1 and a maximum range of 4 .

$$
1 \leq R N E_{\text {Total }}^{i, t} \leq 4
$$

Also, taking the numerical valuation $\left(V N S_{j}^{i, t}\right)$ of each of the variables that make up the Social dimension of a company "i" any, for a year " $t$ ", we can get the rating or rating total numerical $\left(R N S_{\text {Total }}^{i, t}\right)$ from the quotient between the sum of all and each one of the individual numerical valuations of that dimension and the number of variables (10) that integrate it.

$$
\text { (8) } R N S_{\text {Total }}^{i, t}=\frac{\sum_{j=1}^{10} V N S_{j}^{i, t}}{10}
$$

This rating or total numerical rating corresponding to this Social dimension will range between a minimum range of 1 and a maximum range of 4 .

$$
1 \leq R N S_{\text {Total }}^{i, t} \leq 4
$$

Finally, through the numerical valuation $\left(V N G_{j}^{i, t}\right)$ of each of the variables that make up the Governance dimension of any company "i", for a year "t", we can obtain the rating or rating total numerical $\left(R N G_{\text {Total }}^{i, t}\right)$ from the quotient between the sum of all and each one of the individual numerical valuations of that dimension and the number of variables (10) that make it up.

$$
\text { (9) } R N G_{\text {Total }}^{i, t}=\frac{\sum_{j=1}^{10} V N G_{j}^{i, t}}{10}
$$

This rating or total numerical rating corresponding to this Social dimension will range between a minimum range of 1 and a maximum range of 4 .

$$
1 \leq R N G_{\text {Total }}^{i, t} \leq 4
$$


Consequently, the rating or numerical rating $\left(R N_{\text {Global }}^{i, t}\right)$ of the whole company "i" for the period " $t$ " will always be the result of calculating the simple arithmetic mean of the numerical ratings of the three dimensions.

$$
\text { (10) } R N_{\text {Global }}^{i, t}=\frac{R N E^{i, t}+R N S^{i, t}+R N G^{i, t}}{3}
$$

This numerical rating for the whole company will range between a minimum range of 1 and a maximum range of 4 .

$$
1 \leq R N_{\text {Global }}^{i, t} \leq 4
$$

The conversion of the numerical rating $\left(R N_{G l o b a l}^{i, t}\right)$ of the whole company "i" for the period " $\mathrm{t}$ ", into a rating or joint alphabetical rating $\left(R A_{\text {Global }}^{i, t}\right)$ for that company and that same period requires defining a transformation function like the one detailed below:

$$
\text { (11) } R A_{\text {Global }}^{i, t}=f\left[R N_{\text {Global }}^{i, t}\right]
$$

Accordingly, once the global numerical rating has been obtained, this value is converted into an A, B, C or D rating (where A is the best and D the worst), according to the scaling detailed below:

$$
\text { So that }\left\{\begin{array}{c}
1.75<R N_{\text {Global }}^{i, t} \leq 1 \rightarrow f\left[R N_{\text {Global }}^{i, t}\right]=D=R A_{\text {Global }}^{i, t} \\
2.5<R N_{\text {Global }}^{i, t} \leq 1.75 \rightarrow f\left[R N_{\text {Global }}^{i, t}\right]=C=R A_{\text {Global }}^{i, t} \\
3.25<R N_{\text {Global }}^{i, t} \leq 2.5 \rightarrow f\left[R N_{\text {Global }}^{i, t}\right]=B=R A_{\text {Global }}^{i, t} \\
4 \leq R N_{\text {Global }}^{i, t} \leq 3.25 \rightarrow f\left[R N_{\text {Global }}^{i, t}\right]=A=R A_{\text {Global }}^{i, t}
\end{array}\right.
$$

\section{Conclusions}

The ESG concept offers a pragmatic vision of social responsibility in which the economic benefit is accepted as the main objective of the companies regardless of their geographical location. This interpretation makes ESG a more appropriate concept than CSR when developing an analysis system for the relationship between companies and their context. This work shows that the relationship of the company with its context has great strategic importance. Firstly, it has been shown that it can be analysed in quantitative terms. Secondly, it has observed that its monetary value can be brought to light. Both points represent an innovation in the field of corporate social responsibility.

The ESG Audit model described in this article shows that the Environmental, Social and Governance dimensions can be parameterized in a verifiable, objective, quantifiable and comparable manner. This supposes an innovation with respect to the current methodologies of analysis of the corporate social responsibility.

For each of the 30 variables into which the model is broken down, a quantification process has been designed that allows it to subsequently be assigned an alphabetical qualification. This result is easily comparable between different companies and for different times at the same company, fulfilling the third secondary objective. For each of the three pillars, Environmental, Social and Governance, 10 descriptive variables have been defined. For each of the variables, a function has been designed that allows 
us to transform the verifiable information provided by the audit questionnaire into an alphabetical qualification where $\mathrm{A}$ is the best score and $\mathrm{D}$ the worst. For the design of this rating system, the methodology used by risk rating agencies was taken as a reference.

Once the rating of each variable has been defined, a system of transformation formulas allows us to convert the alphabetical qualification into a numerical value to calculate the overall ESG rating of the audited company. The global rating will also be expressed with an alphabetical rating where $\mathrm{A}$ is the best score and $\mathrm{D}$ the worst.

The ESG Audit model thus presents synthesized and easily comparable information on the relationship of a company with its environmental, social and corporate governance environment. The individual ratings allow to analyse in detail the strengths and weaknesses of the ESG of the audited company. Overall rating facilitates the production of statistics and comparison of the ESG between different companies or for the same company in different times.

The model can be useful to systemize measurement of ESG and enable agreement among the main trade unions, consumer associations and environmental organizations in each country. This will help ensure that all the information used is true.

ESG Audit model gives a more complete picture of CSR. The more concrete each variable is, the more detailed will be the image that will be obtained from the company. However, this work must at all times adhere to the criterion of simplicity. We should be very careful also to avoid variables that overlap and thus distort the image by creating overweighting in some ESG aspects.

Finally, the weighting and qualification processes should be improved. With the indispensable collaboration of experts in different fields of the ESG, the scales of assessment for each variable should be established. This should enable individual values to be obtained that are as accurate as possible according to the needs of society and the capabilities of companies.

Our model is only a theoretical proposal because it has not been applied yet to value any company. So we do not offer any empirical data at this moment. Anyway, the model, at current stage, provides a useful guide to assess the fundamentals of CSR.

\section{Bibliography}

Barko, T., Cremers, M. \& Renneboog, L. (2017). Shareholder Engagement on Environmental, Social, and Governance Performance. ECGI Working Paper Series in Finance, Working Paper $\mathrm{N}^{\circ}$ 509, August.

Barnard, C. (1938). The Functions of the Executive. Harvard University Press. Cambridge, MA.

Bhattacharya, C. (2009). Corporate Social Responsibility: It's All about Marketing. Forbes.

Bowen, H.R. (1953). Social Responsibilities of the Businessman. Series: Ethics and Economics for Society. New York, Harpers.

Brondoni S.M. (2010). Intangibles, Global Networks \& Corporate Social Responsibility, Symphonya. Emerging Issues in Management (symphonya.unimib.it), 2, 6-24.

http://dx.doi.org/10.4468/2010.2.02brondoni

Cancino, C. \& Morales, M. (2008). Responsabilidad Social Empresarial. Serie Documento Docente $\mathrm{N}^{\mathrm{o}} 1$, Facultad de economía y negocios de la Universidad de Chile.

Cedillo Torres, C., García-French, M., Hordijk, R. \& Nguyen, K. (2012). Four Case Studies on Corporate Social Responsibility: Do Conflicts Affect a Company’s Corporate Social Responsibility 
Policy? Volume 8, Issue 3 (November), available at: http://www.utrechtlawreview.org. (September, 2017).

\section{http://doi.org/10.18352/ulr.205}

Chatterji, A. \& Levine, D. (2006). "Breaking down the wall of codes: evaluating non-financial performance measurement”, California Management Review, 48(2) pp. 29-51.

http://doi.org/10.2307/41166337

Comission of the European Communities (2001). "Green Paper: Promoting a European Framework for Corporate Social Responsibility". Commission of the European Communities, Brussels.

Crane, A. \& Matten, D. (2014). Four big problems with "Creating Shared Value". Available at: www.c raneandmatten.blogspot.com (September, 2017).

CSR Managers Survey (2015). How CSR has influenced Central European societies and economies. Lessons learnt and future trends. CSR Managers Survey in Central Europe. Available at: https://www2.deloitte.com/content/dam/Deloitte/lt/Documents/strategy/LT_CSR_Managers_Repo rt.pdf (October 2017).

Davis, K. (1960). "Can business afford to ignore social responsibilities?" California Management Review, Vol. 2 No. 3, Spring, 1960; (pp. 70-76).

https://doi.org/10.2307/41166246

Dyck, A., Lins, K., Roth, L. and Wagner, H. (2015). Do Institutional Investors Drive Corporate Social Responsibility? International Evidence. Working paper Bocconi University.

Edmans, A. (2012). The Link Between Job Satisfaction and Firm Value, With Implications for Corporate Social Responsibility. The Academy of Management Perspectives, 26(4), 1-19.

https://doi.org/10.5465/amp.2012.0046

Flammer, C. (2015). "Does Corporate Social Responsibility Lead to Superior Financial Performance? A Regression Discontinuity Approach”. Management Science, 61(11), 2549-2568. https://doi.org/10.1287/mnsc.2014.2038

Goldberg, M. (2009). "Measuring the immeasurable?: Constructing an index of CSR practices and CSR performance in 20 countries". Scandinavian Journal of Management, vol, 25, March, 10-22. https://doi.org/10.1016/j.scaman.2008.10.003

Hartman, L. P. \& Morland, M.P. (2007). "Exploring the Global Reporting Initiatives (GRI) Guidelines as a Model for Triple Bottom-Line Reporting". African Journal of Business Ethics, 2 (1), pp. 4557.

Mosca F., Tamborrini P. \& Casalegno C. (2015). From Corporate Social Responsibility to Systemic Design: How to Compete by Leveraging the Value System, Symphonya, Emerging Issues in Management, 2. http://dx.doi.org/10.4468/2015.2.04mosca.tamborrini.casalegno

Keeble, J., Topiol, S. \& Berkeley, S. (2003). Using Indicators to Measure Sustainability Performance at a Corporate and Project Level, Journal of Business Ethics, 44, pp. 149- 158.

https://doi.org/ 10.1023/A:1023343614973

Knox, S. \& Maklan, S. (2004). Corporate Social Responsibility: Moving Beyond Investment Towards Measuring Outcomes, European Management Journal, 22(5), pp. 508-516.

https://doi.org/10.1016/j.emj.2004.09.009

Kolk, A. (2004). A decade of sustainability reporting: developments and significance, International Journal of Environment and Sustainable Development, 3 (1).

https://doi.org/10.1504/IJESD.2004.004688

Krep, T. (1940). Measurement of the Social Performance of Business. U.S. Government Printing Office. Washington.

Lee, K.-H., Cin, B. C., and Lee, E. Y. (2016). Environmental Responsibility and Firm Performance: The Application of an Environmental, Social and Governance Model. Business Strategy and the Environment, 25: 40-53.

https://doi.org/10.1002/bse.1855 
Liern, V., Pérez-Gladish, B. \& Méndez-Rodríguez, P. (2017). Measuring Social Responsibility: A Multicriteria Approach. In: Zopounidis C., Doumpos M. (eds) Multiple Criteria Decision Making. Multiple Criteria Decision Making. Springer, Cham.

https://doi.org/10.1007/978-3-319-39292-9_2

Ligteringen, E. \& Zadek, S. (2005). Future of Corporate Responsability codes, standards and frameworks. Available at: www.accountability21.net/uploadstore/cms/docs/Landscape\%Paper.pdf

Lopatta, K., Jaeschke, R., \& Chen, C. (2017). Stakeholder Engagement and Corporate Social Responsibility (CSR) Performance: International Evidence. Corporate Social Responsibility and Environmental Management.

https://doi.org/10.1002/csr.1440

Mitchell, R.K., Agle, B.R. \& Wood, D.J. (1997). Toward a theory of stakeholder identification and salience: defining the principle of who and what really counts. Academy of Management Review, Vol. 22, pp. 853-886.

\section{https://doi.org/10.5465/amr.1997.9711022105}

Nidumolu, R., Prahalad, C.K. \& Rangaswami, M.R. (2009). Why sustainability is now the key driver of innovation». Harvard Business Review, September.

Porter, M. \& Hills, G. (2011). Measuring Shared Value. How to Unlock Value by Linking Social and Business Results. FSG.

Porter, M., \& Kramer, M. (2011). Creating Shared Value. Harvard Business Review.

Rasche, A. (2009). Toward a model to compare and analyze accountability standards: the case of the UN Global Compact, Corporate Social Responsibility and Environmental Management, 16, pp. 192-205

https://doi.org/ 10.1002/csr.202

Rosanas, J. (2006). Indicadores de gestión, incentivos, motivación y ética en el control de gestión, Occasional Paper, OP 06/11, IESE Business School.

Rosanas, J. (2010). Indicators: helpers or hinrances?, IESE Insight, num. 5.

Strandberg, L. (2010). La medición y la comunicación de la RSE: Indicadores y Normas. Cuadernos de la Cátedra "la Caixa" de Responsabilidad Social de la Empresa y Gobierno Corporativo. Num. 9. Diciembre.

Salvioni D. M., \& Bosetti L. (2014). Sustainable Development and Corporate Communication in Global Markets, Symphonya. Emerging Issues in Management (symphonya.unimib.it), 1, 1-19.

http://dx.doi.org/10.4468/2014.1.03salvioni.bosetti

Wang, Z., Hsieh, T.S., \& Sarkis, J. (2017). CSR Performance and the Readability of CSR Reports: Too Good to be True? Corporate Social Responsibility and Environmental Management.

https:/doi.org/10.1002/csr.1440

World Bank Institute (2003). Public Policy for Corporate Social Responsibility. WBI series on corporate responsibility, accountability, and sustainable competitiveness. Washington, D.C.

\footnotetext{
Notes

${ }^{\text {i }}$ Porter \& Kramer (2011) propose three basic actions that enable a balance to be found between social interest and business interest: a) New conception of products and markets, defining markets in terms of unmet needs or social ills and developing profitable products or services that remedy these conditions; b) Redefinition of productivity in the value chain, increasing the productivity of the company through its suppliers by adding social and environmental restrictions in its value chain; c) Development of local clusters, strengthening the competitiveness context in key regions where the company operates in ways that contribute to its growth and productivity.

${ }^{i i}$ For further details see www.unglobalcompact.org/what-is-gc/mission/principles (December, 2017).

iii For further details see www.globalreporting.org/standards (December, 2017).

${ }^{\text {iv }}$ For further details see www.accountability.org/standards/ (December, 2017).
} 
${ }^{v}$ For further details see www.sa-intl.org/index.cfm?fuseaction=Page.ViewPage\&pageId=1689 (December, 2017).

${ }^{\text {vi }}$ For further details see http://foretica.org/tematicas/sge-21/ (December, 2017).

${ }^{\text {vii }}$ For further details see www.iso.org/obp/uit\#iso:std:iso:26000:ed-1:v1:en (December, 2017). 